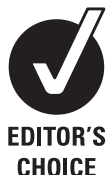

${ }^{1}$ Department of Health Sciences, University of Leicester, Leicester, UK ${ }^{2}$ Department of Cardiovascular Sciences, University of Leicester, Leicester, UK

\section{Correspondence to}

Kate E Lager, Department of Health Sciences, University of Leicester, 22-28 Princess Road West, Leicester LE1 6TP, UK; kel7@le.ac.uk

Received 27 September 2011 Accepted 18 February 2012 Published Online First 20 March 2012

\title{
Quality of secondary prevention measures in TIA patients: a retrospective cohort study
}

\author{
K E Lager, ${ }^{1}$ A Wilson, ${ }^{1}$ K Khunti, ${ }^{1}$ A K Mistri ${ }^{2}$
}

\section{ABSTRACT}

Objective Pharmacological and lifestyle interventions are recommended for the reduction of stroke risk in people who have had a transient ischaemic attack (TIA). This study aimed to investigate the quality of secondary stroke prevention in primary care following diagnosis of TIA in a specialist clinic.

Methods Quality standards were identified from the Royal College of Physicians (RCP) national clinical guideline for stroke and the general practice Quality and Outcomes Framework (QOF) indicators. Patients who were diagnosed with TIA between February and October 2009 were identified from a TIA clinic database. Achievement of quality standards was assessed 12-24 months following clinic attendance.

Results General practices were sent structured data collection forms for 233 patients, and the response rate was $80 \%(n=186)$. Complete data were available for 163 eligible patients (70\%). Overall, 94\% were prescribed antithrombotic medication. QOF standards were achieved by $82 \%$ for blood pressure $(\leq 150$ / $90 \mathrm{~mm} \mathrm{Hg}$ ) and $61 \%$ for total cholesterol ( $\leq 5.0 \mathrm{mmol} / \mathrm{l})$. RCP standards were achieved by $35 \%$ for blood pressure ( $\leq 130 / 80 \mathrm{~mm} \mathrm{Hg}$ ) and $28 \%$ for total cholesterol $(<4.0 \mathrm{mmol} / \mathrm{l})$. RCP standards for the provision of dietary and exercise advice were achieved by $29 \%$ and $34 \%$ of patients, respectively.

Conclusion Only a minority of TIA patients achieved RCP standards whereas QOF standards were generally well achieved. Substantial benefits in terms of stroke prevention stand to be gained if risk factors are managed in line with more stringent RCP standards.

\section{INTRODUCTION}

Stroke is the third leading cause of death and the leading cause of adult disability in the $\mathrm{UK}^{1}$ with an annual cost of $£ 8.9$ billion when direct care, informal care and indirect costs (eg, income loss and social benefit payments) are taken into account. ${ }^{2}$ The early risk of stroke following transient ischaemic attack (TIA) is $9.9 \%, 13.4 \%$ and $17.3 \%$ at 2, 30, and 90 days, respectively. ${ }^{3}$ Furthermore, the 10-year risk of stroke in patients with a 'non-recent' TIA is $18.8 \%{ }^{4}$ The occurrence of TIA therefore represents an important opportunity to implement secondary prevention interventions prior to the occurrence of a potentially disabling stroke.

A number of effective strategies are available for the secondary prevention of stroke. These include blood pressure reduction, ${ }^{5}$ regulation of blood lipids $^{6}$ and prescription of antithrombotic agents. ${ }^{7}$ Additionally, observational studies have reported associations between lifestyle factors and stroke risk. ${ }^{8}$ A modelling study has predicted that $80 \%$ of recurrent vascular events are preventable with improved risk factor management. ${ }^{9}$ However, several studies in patients with cerebrovascular disease have indicated that secondary prevention is often suboptimal. ${ }^{10} 1112$

In the UK, optimal management of TIA is defined by the Royal College of Physicians (RCP) National clinical guideline for stroke. ${ }^{13}$ This comprehensive guideline, developed by the Intercollegiate Stroke Working Party, includes recommendations for secondary stroke prevention (see box 1). All recommendations are based on clinical evidence or, in areas where evidence is unavailable, the consensus views of the Working Party. The nature and strength of the evidence behind each recommendation is available on the RCP website (see http://bookshop.rcplondon.ac.uk/details.aspx? $\mathrm{e}=250$ ).

The general practice Quality and Outcomes Framework (QOF) is a voluntary pay-for-performance scheme introduced in 2004 for UK general practices. This scheme offers financial incentives in return for achieving clinical targets relating to 10 chronic conditions, including stroke and TIA. Secondary prevention targets are specified for blood pressure ( $\leq 150 / 90 \mathrm{~mm} \mathrm{Hg}$ ), total cholesterol (TC) $(\leq 5.0 \mathrm{mmol} / \mathrm{l})$, smoking cessation and the use of antiplatelets and anticoagulant medication. ${ }^{14}$ Since the introduction of QOF, a greater proportion of stroke and TIA patients have been shown to receive secondary prevention treatment; however, practice variation has been reported in the achievement of QOF indicators. ${ }^{15}$

Discrepancies between RCP targets and QOF indicators may represent an organisational barrier contributing to suboptimal secondary prevention. ${ }^{12}$ While RCP recommendations are considered 'gold standard' in terms of quality of stroke care, QOF indicators are regarded as 'relatively simplistic' measures of quality. ${ }^{12}$ However, it should be noted that $\mathrm{QOF}$ indicators are audit criteria rather than targets based on clinical evidence.

Patients with a suspected TIA should receive timely assessment and treatment in a specialist clinic $^{13}$ and $95 \%$ of acute trusts now offer a specialist neurovascular clinic for these purposes. ${ }^{1}$ The Leicestershire TIA Clinic (established on 1 October 2008) was highlighted as an example of good practice by the National Audit Office ${ }^{1}$ and has been used as a sampling frame for this study. Further details about the Leicestershire TIA Clinic are outlined in table 1.

The objectives of this study retrospective cohort study were:

- To describe the quality of secondary prevention care received by TIA patients, following 
Box 1 Secondary prevention themes included in the Royal College of Physicians guideline

1. Identifying risk factors.

2. A personalised, comprehensive approach.

3. Lifestyle measures.

4. Blood pressure (target $\leq 130 / 80 \mathrm{~mm} \mathrm{Hg}$ ).

5. Antithrombotic treatment.

6. Lipid-lowering therapy (target total cholesterol $<4.0 \mathrm{mmol} / \mathrm{l}$ and low-density lipoprotein cholesterol $<2.0 \mathrm{mmol} / \mathrm{l}$ ).

diagnosis at a specialist TIA clinic, according to standards identified from the RCP guidelines and QOF indicators.

- To identify areas for quality improvement.

\section{METHODS}

\section{Design}

This study was carried out as part of a local audit of TIA patient care. Quality standards were identified from the RCP national clinical guideline for stroke ${ }^{13}$ and the general practice QOF indicators $^{14}$ (see tables 2 and 3 for audit criteria). Audit approvals were obtained from University Hospitals of Leicester NHS Trust, Leicester City Primary Care Trust and Leicestershire Country and Rutland Primary Care Trust.

Patients were identified retrospectively using hospital records held on the Leicestershire TIA Clinic database. All patients who attend the Leicestershire TIA Clinic are entered onto this database. The study included patients aged $\geq 18$ who were diagnosed between 1 February and 31 October 2009. The following patients were excluded:

- Patients who had left their registered general practice since their TIA.

- Patients who had died between the date of TIA and date of follow-up data collection.

\section{Data collection}

Baseline data were extracted from the TIA Clinic records by a data clerk (see box 2). Follow-up data were collected on secondary prevention care received 12-24 months after TIA diagnosis (see box 2). For this purpose, structured data collection forms were posted to general practitioners (GPs) for completion using information held on general practice records. If GPs failed to respond to the letter after 3 weeks, a second letter was sent to the practice manager. One reminder telephone call was made to non-responding practice managers after 2 weeks. Since all blood analysis is carried out in secondary care, follow-up data for TC and low-density lipoprotein (LDL) were extracted from hospital databases by a data clerk. Data were analysed using SPSS V.18.

\section{RESULTS \\ Study population}

A total of 722 patients visited the Leicestershire TIA Clinic between 1 February and 31 October 2009 and, of these, 233 $(32 \%)$ were diagnosed with TIA. Twenty-three patients were subsequently excluded due to death $(n=9)$, relocation to another general practice $(n=7)$, unavailability of follow-up data $(n=3)$ and the absence of documentation regarding TIA diagnosis in general practice records $(n=4)$. Complete data were obtained for 163 patients from 72 general practices. This represents $70 \%$ of the original audit sample (see figure 1). The mean (SD) number of patients per practice and per GP were 2.3 (2.3) and $1.3(0.6)$, respectively.

Follow-up data were collected between 12 and 24 months following TIA diagnosis with a mean (SD) follow-up duration of $18( \pm 3)$ months. Time frames for consideration of QOF and RCP standards are 12 months and 15 months, respectively. All 163 patients were followed up $\geq 12$ months post-TIA, whereas a total of 121 patients were followed up $\geq 15$ months post-TIA. The baseline characteristics of the study population are shown in table 4.

\section{Achievement of quality standards}

Achievement of quality standards are shown in tables 2 and 3.

\section{Antithrombotic medication}

At follow-up, RCP and QOF standards for the prescription of antithrombotic medications were achieved by $93 \%$ and $94 \%$ of patients, respectively. Excluding the 14 (9\%) patients on warfarin, there were 137 patients who were prescribed antiplatelet medication; $42 \%$ received both aspirin and dipyridamole, $11 \%$ received clopidogrel alone and $44 \%$ received aspirin alone.

\section{Blood pressure targets and antihypertensive medication}

Ninety-five per cent of patients had their blood pressure documented within the previous 15 months and $82 \%$ achieved the QOF target of $\leq 150 / 90 \mathrm{~mm} \mathrm{Hg}$. Additionally, $90 \%$ of patients had their blood pressure documented in the previous 12 months and $35 \%$ achieved the RCP target of $\leq 130 / 80 \mathrm{~mm} \mathrm{Hg}$.

Table 1 Characteristics of the Leicestershire TIA Clinic

Service organisation

Access

Health professionals involved Investigations performed

Advice provided to patients

Follow-up
Provides a single point of assessment for suspected TIA for all patients living in Leicester, Leicestershire and Rutland, UK (187 general practices, population of 957821 )

Located in secondary care

Open 7 days per week

Referral from GP, emergency department or emergency admissions unit

Risk assessment using the ABCD2 tool required prior to referral

Stroke consultant, clinic nurse, immediate access to vascular surgical consultant for same day assessment

Same day imaging and reporting (Carotid Doppler ultrasound and MRI, where indicated); ECG; blood tests; blood pressure monitoring; BMI calculation

Diagnostic and prognostic information

Counselling on lifestyle modification for the secondary prevention of stroke

No routine follow-up at TIA clinic

TIA patients discharged back to primary care where GPs are advised to manage patients in line with RCP guidelines

RCP targets for blood pressure $(\leq 130 / 80 \mathrm{~mm} \mathrm{Hg})$ and cholesterol $(<4 \mathrm{mmol} / \mathrm{l})$ are routinely set out in discharge letters 
Table 2 Royal College of Physicians (RCP) standards ( $n=163$ patients followed up for $\geq 12$ months)

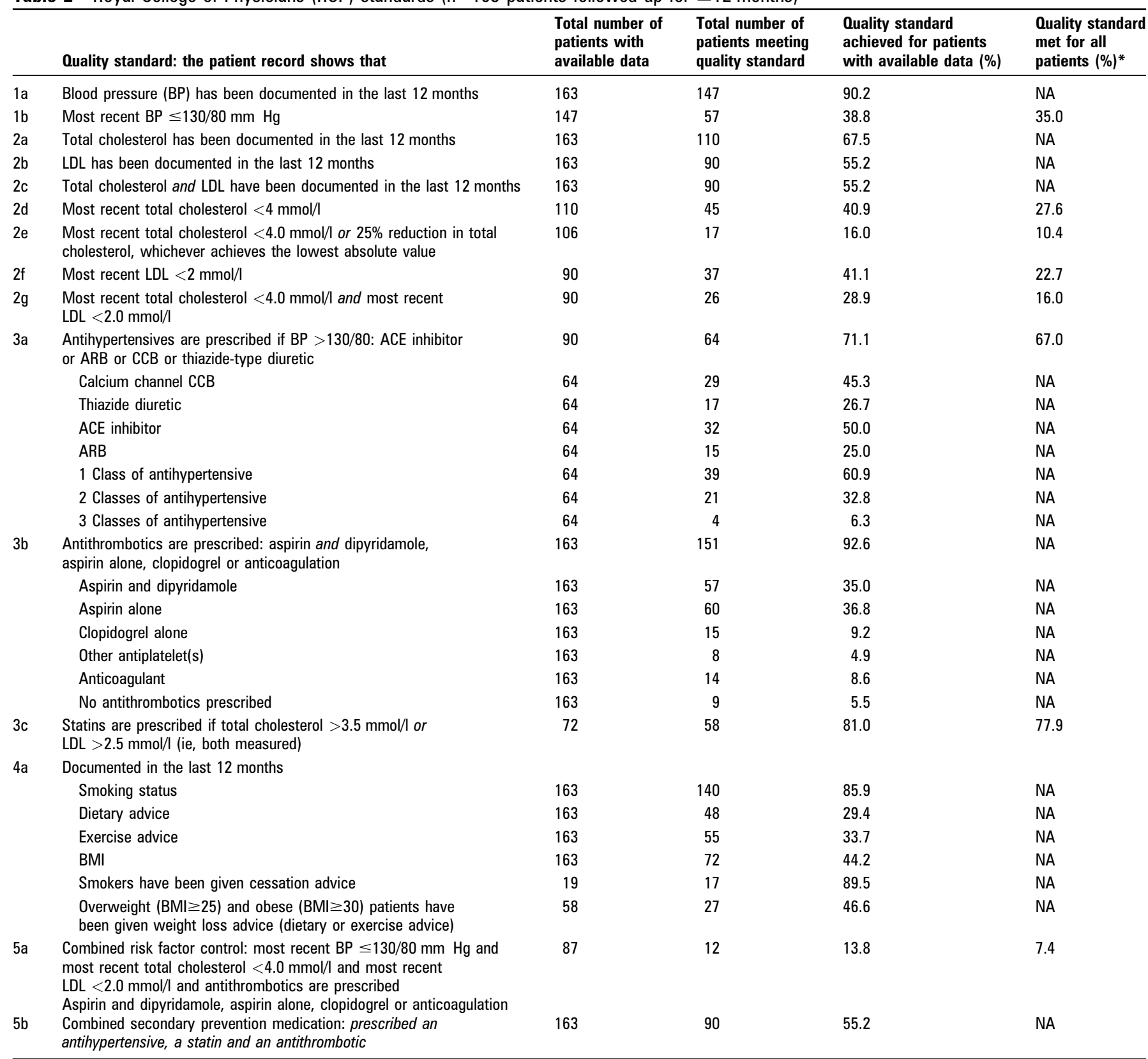

*Assuming that patients with unavailable data did not meet the quality standard.

ACE, angiotensin-converting enzyme; ARB, angiotensin receptor blocker; BMI, body mass index; CCB, calcium channel blocker; LDL, low-density lipoprotein; NA, not applicable.

Seventy-one per cent of patients were prescribed antihypertensive medication according to RCP standards. Overall, 50\% were on an ACE inhibitor, $45 \%$ were on a calcium channel blocker, $27 \%$ were on a thiazide diuretic and $25 \%$ were on an angiotensin receptor blocker. Sixty-one per cent of patients on antihypertensive medication were prescribed one class of medication, whereas $39 \%$ were prescribed two or more recommended medications. Twenty-nine per cent of patients with blood pressure $>130 / 80 \mathrm{~mm} \mathrm{Hg}$ were not prescribed any antihypertensive medications (RCP recommendation: initiate antihypertensives if blood pressure $>130 / 80$ ).

\section{Cholesterol targets and statin medication}

Overall, $78 \%$ of patients had their TC documented in the previous 15 months and $61 \%$ achieved the OOF standard of TC $\leq 5.0 \mathrm{mmol} / 1$. In accordance with RCP guidelines, $55 \%$ of patients had their TC and LDL documented within the previous 12 months, with $16 \%$ achieving RCP standards of TC $<4.0 \mathrm{mmol} / 1$ and $\mathrm{LDL}<2.0 \mathrm{mmol} / 1$.

RCP guidelines recommend that patients should achieve a TC $<4.0 \mathrm{mmol} / \mathrm{l}$ or a $25 \%$ reduction in TC, whichever achieves the lowest value. ${ }^{13}$ In this study, a $25 \%$ reduction in TC was calculated from the time of TIA diagnosis. Although $28 \%$ of patients achieved an absolute target of $<4.0 \mathrm{mmol} / 1$, only $10 \%$ met the full RCP standard when lower targets were considered (ie, also satisfying the criteria of $25 \%$ reduction in TC from baseline). Excluding the $31 \%$ of patients with a past medical history of hypercholesterolaemia at TIA clinic presentation did not substantially change the proportion of patients achieving the full RCP standard (11\%).

A total of 72 patients $(80 \%$ of those with TC and LDL documented in the previous 12 months) were eligible for 
Table 3 Quality and outcome framework (QOF) standards ( $n=121$ patients followed up for $\geq 15$ months)

\begin{tabular}{|c|c|c|c|c|c|}
\hline & Quality standard: the patient record shows that & $\begin{array}{l}\text { Total number of } \\
\text { patients with } \\
\text { available data }\end{array}$ & $\begin{array}{l}\text { Total number of } \\
\text { patients meeting } \\
\text { quality standard }\end{array}$ & $\begin{array}{l}\text { Quality standard } \\
\text { achieved for patients } \\
\text { with available data }(\%)\end{array}$ & $\begin{array}{l}\text { Quality standard } \\
\text { met for all } \\
\text { patients }(\%)^{*}\end{array}$ \\
\hline $1 \mathrm{a}$ & Blood pressure (BP) has been documented in the last 15 months & 121 & 115 & 95.0 & NA \\
\hline $1 b$ & Most recent $\mathrm{BP} \leq 150 / 90 \mathrm{~mm} \mathrm{Hg}$ & 115 & 99 & 86.1 & 81.8 \\
\hline $2 a$ & Total cholesterol has been documented in last 15 months & 121 & 94 & 77.7 & NA \\
\hline $2 b$ & Most recent total cholesterol $\leq 5 \mathrm{mmol} / \mathrm{l}$ & 94 & 74 & 78.7 & 61.1 \\
\hline \multirow[t]{7}{*}{$3 a$} & $\begin{array}{l}\text { Antithrombotics are prescribed: aspirin, clopidogrel, dipyridamole } \\
\text { or a combination; or an anticoagulant }\end{array}$ & 121 & 114 & 94.2 & NA \\
\hline & Aspirin and dipyridamole & 121 & 45 & 37.2 & NA \\
\hline & Aspirin alone & 121 & 43 & 35.5 & NA \\
\hline & Clopidogrel alone & 121 & 11 & 9.1 & NA \\
\hline & Other antiplatelet(s) & 121 & 8 & 6.6 & NA \\
\hline & Anticoagulant alone & 121 & 7 & 5.8 & NA \\
\hline & Not prescribed antithrombotics & 121 & 7 & 5.8 & NA \\
\hline $4 a$ & Smoking status has been documented in the last 15 months & 121 & 85 & 70.2 & NA \\
\hline $4 b$ & Smoking cessation advice has been offered to patients who smoke & 9 & 9 & 100 & NA \\
\hline $5 a$ & $\begin{array}{l}\text { Combined risk factor control: } \\
\text { most recent } B P \leq 150 / 90 \mathrm{~mm} \mathrm{Hg} \text { and } \\
\text { most recent total cholesterol } \leq 5 \mathrm{mmol} / \mathrm{l} \text { and } \\
\text { antithrombotics are prescribed: aspirin, clopidogrel, } \\
\text { dipyridamole or a combination; or an anticoagulant }\end{array}$ & 93 & 66 & 71.0 & 54.5 \\
\hline
\end{tabular}

${ }^{*}$ Assuming that patients with unavailable data did not meet the quality standard.

NA. not applicable.

statins according to RCP guidelines (TC $>3.5 \mathrm{mmol} / \mathrm{l}$ or LDL $>2.5 \mathrm{mmol} / \mathrm{l}$ ). Statins were prescribed in $81 \%$ of these cases. However, 73 patients did not have their TC or LDL documented in the previous 12 months. Assuming that these patients were all eligible for statins, 78\% of a total of 145 potentially eligible patients meet the RCP standard for the prescription of statins.

\section{Box 2 Data collected at baseline and follow-up}

\section{Baseline data}

- Demographic variables (age, gender, ethnicity)

- Blood pressure*

- Cholesterol (total cholesterol (TC), low-density lipoprotein $(\mathrm{LDL}))^{*}$

- Random blood glucose*

- Body mass index*

- Smoking status*

- Prescriptions at discharge (antithrombotic, antihypertensive and lipid-lowering medications) $\dagger$

- Comorbidities (hypertension, hypercholesterolaemia, diabetes, ischaemic heart disease, atrial fibrillation, previous stroke/ transient ischaemic attack (TIA), peripheral vascular disease).

\section{Follow-up data}

- Print out of current prescriptions (antithrombotic, antihypertensive and lipid-lowering medications)

- Date and result of last blood pressure measurement

- Date and results of last cholesterol measurements (TC, LDL)

- Date of most recent lifestyle advice (diet, exercise, smoking cessation).

*Risk factor data were measured at the TIA clinic †Prescription data refer to the medications that a patient was discharged on (ie, following a review of existing medications and including any new medications prescribed at the TIA clinic).

\section{Lifestyle risk factors}

Overall, $34 \%$ and $29 \%$ of patients were reported to have exercise or dietary advice documented in their primary care record during the previous 12 months, respectively. In addition, 72 (44\%) patients had their body mass index (BMI) documented within the same 12-month period. Of these, $36(50 \%)$ were overweight $(B M I \geq 25)$ and $22(31 \%)$ were obese (BMI $\geq 30)$. Forty-seven per cent of overweight or obese patients had weight loss advice (dietary or exercise advice) documented. Smoking status was documented for 140 patients (86\%) during the previous 12 months, of whom 19 (14\%) were smokers, with 17 (90\%) documented to have received cessation advice.

\section{Combined risk factor control}

Of the 87 patients with available data, 12 (14\%) achieved the combined RCP standards of blood pressure $\leq 130 / 80 \mathrm{~mm} \mathrm{Hg}$, TC $<4.0 \mathrm{mmol} / 1, \mathrm{LDL}<2.0 \mathrm{mmol} / 1$ and prescription of antithrombotic medication. When all patients were considered $(\mathrm{n}=163), 7 \%$ achieved this combined standard if it is assumed that patients with missing data failed to achieve the recommended standards. Overall, $55 \%$ of patients were prescribed all three classes of secondary prevention medication (a statin, an antihypertensive and an antithrombotic).

\section{DISCUSSION}

\section{Main findings}

To our knowledge, this study is the first to evaluate the quality of secondary stroke prevention among a population of TIA patients recently diagnosed in a specialist TIA clinic. The results suggest that the achievement of RCP quality standards is suboptimal, whereas achievement of QOF standards was good overall. There are various missed opportunities for maintenance of optimal secondary prevention in this high risk population, and potential areas for quality improvement are identified below.

\section{Antithrombotic medication}

Although the use of antithrombotic medication was good overall, with $94 \%$ of patients prescribed at least one 
Figure 1 Follow-up data collection. $\mathrm{GP}$, general practitioner; TIA, transient ischaemic attack.

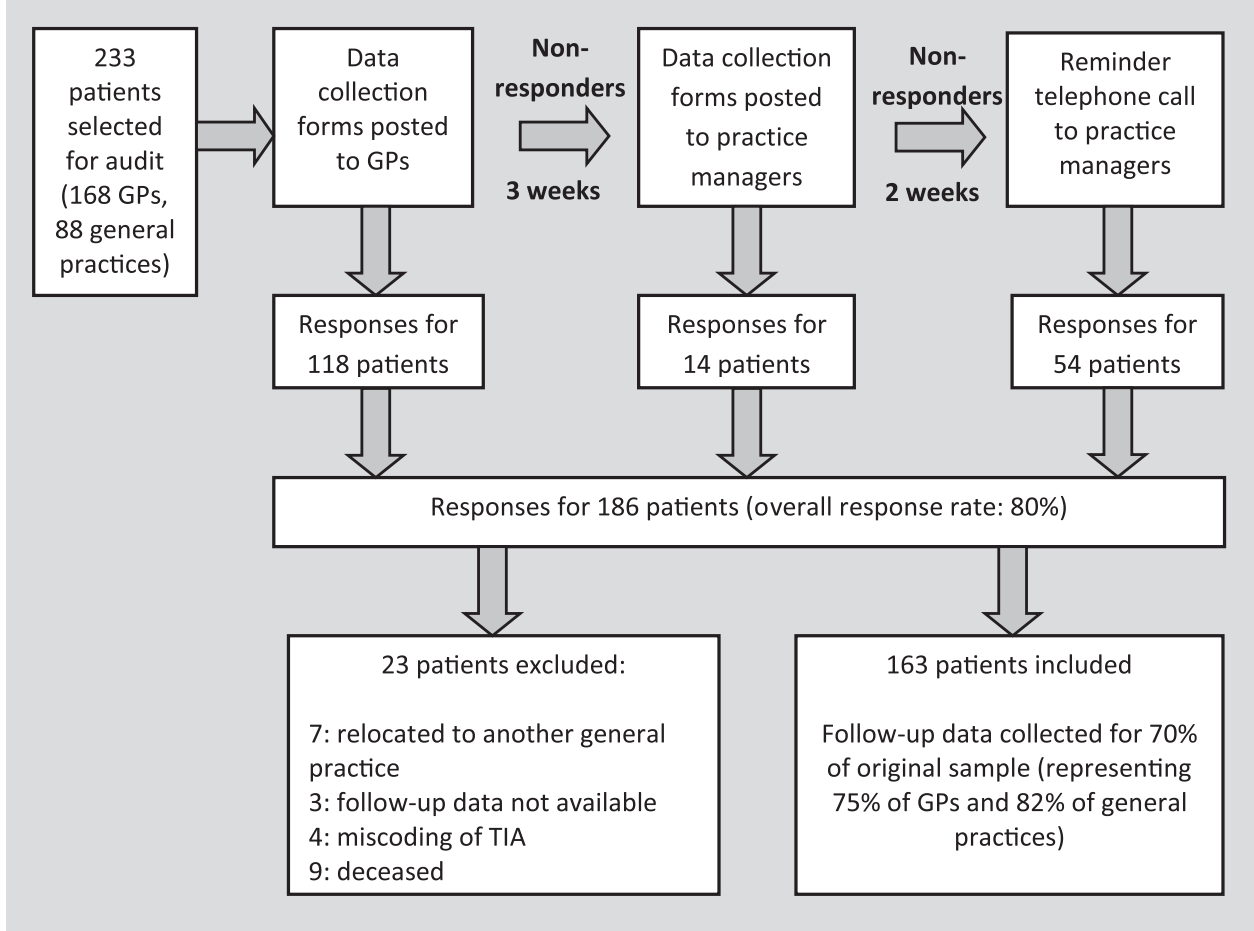

recommended medication, roughly half of those patients on aspirin were not on concomitant dipyridamole (as recommended in the RCP guideline). While a combination of aspirin and dipyridamole has been shown to be more effective for the prevention of ischaemic stroke than aspirin alone, ${ }^{16}$ adverse effects leading to medication discontinuation occur in approximately $16 \%$ of patients. ${ }^{17}$ However, this does not account for the high proportion of patients not prescribed dipyridamole in this study $(50 \%)$.

\section{Blood pressure targets and antihypertensive medication}

Less than $40 \%$ of patients reached the RCP blood pressure standard of $\leq 130 / 80 \mathrm{~mm} \mathrm{Hg}$ and of these, almost $30 \%$ were not prescribed an antihypertensive medication in accordance with RCP guidelines. Reducing blood pressure in TIA patients would have significant clinical benefits for the secondary prevention of stroke since a $9 / 4 \mathrm{~mm} \mathrm{Hg}$ reduction in blood pressure reduces the risk of stroke by $28 \%{ }^{5}$ It is likely that more than one medication will be required to bring blood pressure under control in around $65 \%$ of patients. ${ }^{18}$ Thus, combination therapy is recommended from the outset by some authorities, ${ }^{19}$ though this is uncommon in clinical practice as in this study $(61 \%$ on monotherapy). This makes a strong case for initiation with or progression to combination therapy to improve target blood pressure achievement.

\section{Cholesterol targets and statin medication}

At follow-up, only $28 \%$ of patients achieved a TC $<4 \mathrm{mmol} / 1$ (RCP standard) whereas $61 \%$ achieved a TC $\leq 5 \mathrm{mmol} / \mathrm{l}$ (QOF standard). These data suggest that GPs may not lower TC aggressively once QOF indicators have been met. Furthermore, nearly half of all patients (45\%) did not have their LDL measured within the previous 12 months, and only $23 \%$ achieved the RCP standard (LDL $<2 \mathrm{mmol} / \mathrm{l})$. Intensive cholesterol lowering, although only 'marginally' beneficial for stroke prevention, has significant benefits for the prevention of cardiovascular events and is therefore recommended in TIA patients. ${ }^{6}$
The RCP guideline recommends a $25 \%$ reduction in TC or a target of TC $<4.0 \mathrm{mmol} / 1$, whichever achieves the lowest absolute value. Similarly, a $30 \%$ reduction in LDL or a target of $\mathrm{LDL}<2.0 \mathrm{mmol} / \mathrm{l}$ is recommended. However, baseline TC and LDL values have not been defined; these could be interpreted as pretreatment values or the values at the time of TIA diagnosis. The resulting ambiguity, combined with the need for GPs to set individual patient targets, may contribute to suboptimal cholesterol lowering. A simplified treatment target may facilitate GP adherence to this standard.

\section{Lifestyle risk factors}

The documentation of lifestyle advice was generally poor. Lifestyle data are likely to be entered in electronic patient records as free-text and are generally of lower quality than coded data (eg, prescribing and diagnostic data). ${ }^{20}$ However, available data indicated that rates of overweight and obesity were high (81\%) and meta-analysis has demonstrated that this puts patients at high risk of stroke. ${ }^{21}$ Implementation of the National Health Service Health Checks programme, which incorporates strategies for weight management and communication of risk, could facilitate the management of TIA patients. ${ }^{22}$

\section{Comparison with other studies}

Few studies have examined the status of secondary prevention specifically among TIA patients. Rather, studies have presented combined data for heterogeneous populations of stroke and TIA patients. ${ }^{11} 12$ However, the management of specific risk factors may differ in TIA patients when compared with stroke patients for example, Ramsay et al found that a diagnosis of TIA, as opposed to stroke, was associated with lower usage of blood pressure lowering medication in a cohort of older British men. ${ }^{10}$

In a cohort of stroke and TIA patients attending a rapid access stroke clinic or undergoing carotid endarterectomy, only $28 \%$ achieved a blood pressure $\leq 130 / 80 \mathrm{~mm} \mathrm{Hg}$ and $22 \%$ achieved a TC $<4.0 \mathrm{mmol} / \mathrm{l}^{11}$ Although the proportions of patients achieving these standards are lower than those reported in our 
Table 4 Baseline characteristics of 163 patients diagnosed with TIA in a specialist TIA clinic

\begin{tabular}{|c|c|c|}
\hline Characteristics of patients at baseline & $\begin{array}{l}\% \text { Or } \\
\text { mean (SD) }\end{array}$ & $\begin{array}{l}\text { Missing } \\
\text { data } \%\end{array}$ \\
\hline \multicolumn{3}{|l|}{ General practice data } \\
\hline $\begin{array}{l}\text { Number of patients per general practitioner, } \\
\text { mean (SD) }\end{array}$ & $1.29(0.58)$ & \\
\hline Number of patients per practice, mean (SD) & $2.26(2.28)$ & \\
\hline \multicolumn{3}{|l|}{ Demographic data } \\
\hline Age, mean (SD) & $71.5(12.4)$ & \\
\hline Male (\%) & 54.6 & \\
\hline \multicolumn{3}{|l|}{ Ethnicity (\%) } \\
\hline Caucasian & 85.9 & 4.9 \\
\hline Asian & 9.2 & 4.9 \\
\hline BMI, mean (SD) & $27.7(4.7)$ & 7.4 \\
\hline \multicolumn{3}{|l|}{ Self reported smoking status (\%) } \\
\hline Current & 19.0 & 0.6 \\
\hline Previous & 38.7 & 0.6 \\
\hline Never & 41.7 & 0.6 \\
\hline \multicolumn{3}{|c|}{ Comorbidities: past medical history at initial diagnosis (\%) } \\
\hline Hypertension & 50.9 & \\
\hline Hypercholesterolaemia & 31.3 & \\
\hline Diabetes & 13.5 & \\
\hline Ischaemic heart disease & 6.1 & \\
\hline Atrial fibrillation & 6.7 & \\
\hline Previous stroke/TIA & 17.8 & \\
\hline Peripheral vascular disease & 2.5 & \\
\hline \multicolumn{3}{|l|}{ Achievement of RCP standards } \\
\hline Most recent $\mathrm{BP} \leq 130 / 80 \mathrm{~mm} \mathrm{Hg} \mathrm{( \% )}$ & 25.2 & \\
\hline Most recent total cholesterol <4 mmol/l (\%) & 23.9 & 2.5 \\
\hline Antihypertensives are prescribed if $\mathrm{BP}>130 / 80$ & 73.0 & \\
\hline $\begin{array}{l}\text { Antithrombotics are prescribed: aspirin } \\
\text { AND dipyridamole, aspirin alone, clopidogrel } \\
\text { or anticoagulation (\%) }\end{array}$ & 97.5 & \\
\hline $\begin{array}{l}\text { Statins are prescribed if total cholesterol } \\
>3.5 \mathrm{mmol} / \mathrm{l}(\%)\end{array}$ & 88.9 & \\
\hline \multicolumn{3}{|l|}{ Achievement of QOF Standards } \\
\hline Most recent $\mathrm{BP} \leq 150 / 90 \mathrm{~mm} \mathrm{Hg}(\%)$ & 62.6 & \\
\hline Most recent total cholesterol $\leq 5 \mathrm{mmol} / \mathrm{l}(\%)$ & 57.9 & 2.5 \\
\hline $\begin{array}{l}\text { Antithrombotics are prescribed: aspirin, } \\
\text { clopidogrel, dipyridamole or a combination; or } \\
\text { an anticoagulant (\%) }\end{array}$ & 99.4 & \\
\hline
\end{tabular}

$\mathrm{BMI}$, body mass index; BP, blood pressure; QOP, quality and outcome framework; RCP, Royal College of Physicians; TIA, transient ischaemic attack.

study (35\% and $28 \%$, respectively), data were collected 6 months post-TIA (compared with 12-18 months post-TIA in our study) with less time therefore available to achieve risk factor targets. Moreover, this study collected data in 2004-2005 compared with our more recent data from 2009 to 2010.

\section{Strengths and limitations}

This study used a collaborative method to collect follow-up data from general practices. A short (5 min) data collection form was devised and resulted in a response rate of $80 \%$. Similar surveys of UK general practices have reported response rates ranging from $46 \%{ }^{23}$ to $70 \%{ }^{24}$ the high response rate achieved in our study was facilitated by the use of a short questionnaire with repeat mailing and follow-up telephone contact. ${ }^{25}$

Despite the high response rate, a limitation of this study concerned the self-selection of general practices. Non-responding practices may have differed systematically from responding practices. Second, data on medication contraindications were not documented in this study. Adverse drug effects are common in primary care settings and may result in medication discontinuation. ${ }^{26}$ It is therefore likely that this study has under- estimated the proportion of patients who were prescribed appropriate secondary prevention therapy. Finally, this study did not collect details on the specific nature of lifestyle advice provided to TIA patients for the purposes of secondary stroke prevention. Consequently, the content and comprehensiveness of lifestyle advice cannot be evaluated in relation to RCP guidelines.

This study evaluated the status of secondary prevention in primary care following diagnosis of TIA at one regional TIA clinic. Although such clinics are widely implemented, their precise characteristics are subject to regional variation and may be expected to differ in terms of access to services, comprehensiveness of services and service providers. ${ }^{27}$ Therefore, further research is required to establish whether the results of this study are generalisable to other TIA populations.

\section{CONCLUSION}

In the UK, Department of Health initiatives have led to the widespread implementation of rapid-access TIA clinics, which have been shown to reduce the short-term risk of stroke and are cost-effective. ${ }^{28}$ However, this study has demonstrated that subsequent monitoring and optimisation of vascular risk factor management in primary care remain suboptimal. The findings exclusively in people who have had a TIA are in agreement with previous research in more heterogeneous groups (including people with TIA or stroke) in highlighting inconsistencies between the achievement of QOF indicators and RCP targets. ${ }^{12}$

Further research is required to identify the potential barriers and enablers to optimising secondary prevention following a diagnosis of TIA. GPs may be unaware of stringent RCP targets or reluctant to adhere to them due to concerns about adverse effects in elderly patients ${ }^{29}$ and uncertainties regarding the applicability of underpinning evidence. ${ }^{30}$ Additionally, it has

\section{Main messages}

Secondary prevention care for transient ischaemic attack (TIA) patients is currently in line with the general practice Quality and Outcomes Framework indicators.

- However, secondary prevention care deviates from the 'gold standard' recommendations in the Royal College of Physicians national clinical guideline for stroke.

- Key suggestions for improving quality of secondary prevention post-TIA include: strategies to improve dipyridamole continuation; early consideration of combination antihypertensive therapy; simplification of lipid targets; and a review of Quality and Outcomes Framework targets with a view to intensifying blood pressure and lipid targets.

\section{Current research questions}

What are the barriers to secondary stroke prevention after a transient ischaemic attack (TIA)?

- What interventions are effective for optimal long-term secondary stroke prevention following TIA?

- How should follow-up services be organised in order to optimise secondary prevention after a TIA? 


\section{Key references}

- Intercollegiate Stroke Working Party. National Clinical Guideline for Stroke. 2008. http://bookshop.rcplondon.ac.uk/ contents/6ad05aab-8400-494c-8cf4-9772d1d5301b.pdf (accessed 19 Jan 2012).

- NHS Confederation. Quality and Outcomes Framework Guidance for GMS Contract 2011/12 Delivering Investment General Practice. 2011. http://www.nhsemployers.org/ Aboutus/Publications/Documents/OOF_guidance_GMS_contract_2011_12.pdf (accessed 19 Jan 2012).

- Department of Health. Progress in Improving Stroke Care. 2010. http://www.nao.org.uk/publications/0910/stroke.aspx (accessed 19 Jan 2012).

- Hackam DG, Spence JD. Combining multiple approaches for the secondary prevention of vascular events after stroke: a quantitative modeling study. Stroke 2007;38:1881-5.

- Merwick A, Kelly PJ. Transient ischaemic attack clinics and management of transient ischaemic attacks. Curr Opin Neurol 2011;24:50-8.

yet to be demonstrated that more stringent blood pressure targets are achievable in a primary care setting. ${ }^{31}$

Ongoing follow-up in secondary care or by specialist nurses' may facilitate adherence to a more stringent target-based approach to secondary prevention. Currently, a 6 week review of all patients following a TIA is being encouraged by the Department of Health 'Accelerating Stroke Improvement' (ASI) programme, but there remains lack of clarity as to whether this should occur in primary or specialist care. Achievement of QOF criteria is not sufficient for the effective secondary prevention of stroke and more emphasis could be placed on adherence to RCP guidelines. In accordance with a recent report from the National Audit Office, ${ }^{1}$ the findings from this study provide strong supportive evidence that a review of OOF targets are indicated in order to better align these with RCP recommendations.

Acknowledgements We would like to thank Dr David Eveson (collaborator) for assisting with data extraction.

Contributors All authors contributed to the conception and design of the study. $\mathrm{KL}$ and $\mathrm{AM}$ and carried out data extraction and data analysis. All authors contributed to drafting and revising the manuscript.

Funding This study is supported by funds from the Department of Health Sciences and the Department of Cardiovascular Sciences, University of Leicester.

Competing interests $\mathrm{AM}$ and $\mathrm{KK}$ have received sponsorship for attending conferences and honorariums from pharmaceutical companies that manufacture drugs for the secondary prevention of stroke.

Ethics approval This study was carried out as part of an audit of TIA patient care. Audit approval was obtained from University Hospitals of Leicester NHS Trust, Leicester City Primary Care Trust (PCT) and Leicestershire Country and Rutland PCT. Ethics Committee approval was not required.

Provenance and peer review Not commissioned; externally peer reviewed.

\section{REFERENCES}

1. Department of Health. Progress in Improving Stroke Care. 2010. http://www.nao. org.uk/publications/0910/stroke.aspx (accessed 19 Jan 2012).

2. Saka 0, McGuire A, Wolfe C. Cost of stroke in the United Kingdom. Age Ageing 2009;38:27-32

3. Wu CM, McLaughlin K, Lorenzetti DL, et al. Early risk of stroke after transient ischemic attack: a systematic review and meta-analysis. Arch Intern Med 2007:167:2417-22.
4. Clark TG, Murphy MF, Rothwell PM. Long term risks of stroke, myocardial infarction, and vascular death in "low risk" patients with a non-recent transient ischaemic attack. J Neurol Neurosurg Psychiatry 2003;74:577-80.

5. PROGRESS Collaborative Group. Randomised trial of a perindopril-based bloodpressure-lowering regimen among 6,105 individuals with previous stroke or transient ischaemic attack [Erratum appears in Lancet 2001 Nov 3;358(9292):1556]. Lancet 2001;358:1033-41.

6. Manktelow BN, Potter JF. Interventions in the management of serum lipids for preventing stroke recurrence. Cochrane Database Syst Rev 2009;8:CD002091.

7. Antithrombotic Trialists' Collaboration. Collaborative meta-analysis of randomised trials of antiplatelet therapy for prevention of death, myocardial infarction, and stroke in high risk patients. BMJ 2002;324:71-86.

8. Galimanis A, Mono ML, Arnold M, et al. Lifestyle and stroke risk: a review. Curr Opin Neurol 2009;22:60-8.

9. Hackam DG, Spence JD. Combining multiple approaches for the secondary prevention of vascular events after stroke: a quantitative modeling study. Stroke 2007;38:1881-5.

10. Ramsay SE, Whincup PH, Wannamethee SG, et al. Missed opportunities for secondary prevention of cerebrovascular disease in elderly British men from 1999 to 2005: a population-based study. J Public Health (Oxf) 2007;29:251-7.

11. Johnson $\mathbf{P}$, Rosewell M, James MA. How good is the management of vascular risk after stroke, transient ischaemic attack or carotid endarterectomy? Cerebrovasc Dis 2007;23:156-61.

12. Williams $\mathbf{P H}$, de Lusignan S. Does a higher 'quality points' score mean better care in stroke? An audit of general practice medical records. Inform Prim Care 2006:14:29-40.

13. Intercollegiate Stroke Working Party. National Clinical Guideline for Stroke. 2008. http://bookshop.rcplondon.ac.uk/contents/6ad05aab-8400-494c-8cf49772d1d5301b.pdf (accessed 19 Jan 2012).

14. NHS Confederation. Quality and Outcomes Framework Guidance for GMS Contract 2011/12 Delivering Investment General Practice. 2011. http://www.nhsemployers. org/Aboutus/Publications/Documents/OOF guidance GMS contract 2011 12.pdf (accessed 19 Jan 2012)

15. National Audit Office DoH. Reducing Brain Damage: Faster Access to Better Stroke Care. 2005. http://www.nao.org.uk/publications/0506/reducing brain damage.aspx (accessed 19 Jan 2012)

16. De Schryver EF, Algra A, van Gijn J. Dipyridamole for preventing stroke and other vascular events in patients with vascular disease. Cochrane Database Syst Rev 2007; 18:CD001820.

17. Sacco RL, Diener HC, Yusuf S, et al; PRoFESS Study Group. Aspirin and extendedrelease dipyridamole versus clopidogrel for recurrent stroke. N Engl J Med 2008;359:1238-51.

18. Schrader J, Lüders S, Kulschewski A, et al. Morbidity and Mortality after stroke, Eprosartan compared with Nitrendipine for secondary prevention: principal results of a prospective randomized controlled study (MOSES). Stroke 2005;36:1218-26.

19. Williams B, Poulter NR, Brown MJ, et al. Guidelines for management of hypertension: report of the fourth working party of the British Hypertension Society, 2004-BHS IV. J Hum Hypertens 2004;18:139-85.

20. Thiru K, Hassey A, Sullivan F. Systematic review of scope and quality of electronic patient record data in primary care. BMJ 2003;326:1070.

21. Strazzullo P, D'Elia L, Cairella G, et al. Excess body weight and incidence of stroke: meta-analysis of prospective studies with 2 million participants. Stroke 2010;41: e418-26.

22. Department of Health. NHS Health Check: Vascular Risk Assessment and Management. 2009. http://www.dh.gov.uk/prod_consum_dh/groups/ dh_digitalassets/documents/digitalasset/dh 098410.pdf (accessed 19 Jan 2012)

23. Royal College of Surgeons in Ireland and Trinity College Dublin. National Audit of Stroke Care Community Audit: National Survey of General Practitioners. 2006. http://www.irishheart.ie/media/pub/strokereports/ihf gp report may 2007.pdf (accessed 19 Jan 2012).

24. Pierce $\mathbf{M}$, Agarwal G, Ridout D. A survey of diabetes care in general practice in England and Wales. Br J Gen Pract 2000;50:542-5.

25. Nakash RA, Hutton JL, Jørstad-Stein EC. Maximising response to postal questionnaires - a systematic review of randomised trials in health research. BMC Med Res Methodol 2006;6:5.

26. Gandhi TK, Weingart SN, Borus J, et al. Adverse drug events in ambulatory care. N Engl J Med 2003;348:1556-64.

27. Beech PF, Greenhalgh JF, Thornton MF, et al. A survey of the practice of stroke doctors in developing transient ischaemic attack services in the UK. J Eval Clin Pract 2007:13:395-9.

28. Merwick A, Kelly PJ. Transient ischaemic attack clinics and management of transient ischaemic attacks. Curr Opin Neurol 2011;24:50-8.

29. Kaplan RC, Tirschwell DL, Longstreth WT Jr, et al. Blood pressure level and outcomes in adults aged 65 and older with prior ischemic stroke. J Am Geriatr Soc 2006; $54: 1309-16$.

30. Mant J, McManus RJ, Hare R. Applicability to primary care of national clinical guidelines on blood pressure lowering for people with stroke: cross sectional study. BMJ 2006:332:635-7.

31. Fletcher K, Mant J, McManus R, et al. Protocol for Past BP: a randomised controlled trial of different blood pressure targets for people with a history of stroke of transient ischaemic attack (TIA) in primary care. BMC Cardiovasc Disord 2010;10:37. 